\title{
Quality of Life, Depression, Sexual Dysfunction and Work Absenteeism in Relapsing-Remitting Multiple Sclerosis Patients Starting Glatiramer Acetate as First-Line Treatment: A Prospective Cohort Study
}

Javier Olascoaga-Urtaza ${ }^{1}$, Virginia Meca-Lallana ${ }^{2}$, Rocío Hernández-Clares ${ }^{3}$, Lluís Ramió-Torrentà ${ }^{4}$, Domingo Pérez ${ }^{5}$, Ana María Alonso ${ }^{6}$, Gerardo Joaquín Soriano $^{7}$, Jose Abos-Navarro ${ }^{8}$, Gisela Martín ${ }^{9}$, Francisco Padilla ${ }^{10}$, Noemi Llopis ${ }^{11}$, Rainel Sánchez-de la Rosa ${ }^{11^{*}}$

${ }^{1}$ Department of Neurology, Hospital Donostia, Paseo Doctor Beguiristain, 109, 20014 San Sebastián, Spain

${ }^{2}$ Department of Neurology, Hospital Universitario de La Princesa, Calle de Diego de León, 62, 28006 Madrid, Spain

${ }^{3}$ Department of Neurology, Hospital Clínico Universitario Virgen de la Arrixaca, Carretetra Madrid-Cartagena, S/N, 30120 El Palmar, Spain

${ }^{4}$ Department of Neurology-Instituto de Investigación Biomédica de Girona, Hospital Universitari de Girona Doctor Josep Trueta, Avenida de França, S/N, 17007 Girona, Spain

${ }^{5}$ Department of Neurology, Hospital el Bierzo, Calle Médicos sin Fronteras, 7, 24411 Ponferrada, Spain

${ }^{6}$ Department of Neurology, Hospital Regional Universitario Carlos Haya, Avenida Carlos Haya, S/N, 29010 Málaga, Spain

${ }^{7}$ Department of Neurology, Hospital de Navarra, Calle de Irunlarrea, 3, 31008 Pamplona, Spain

${ }^{8}$ Department of Neurology, Hospital Althaia, Calle Doctor Joan Soler, 1-3, 08243 Manresa, Spain

${ }^{9}$ Department of Neurology, Hospital de Tortosa Verge de la Cinta, Carrer de les Esplanetes, 44-58, 43500 Tortosa, Spain

${ }^{10}$ Department of Neurology, Hospital Universitario Virgen de la Victoria, Campus de Teatinos, S/N, 29010 Málaga, Spain

${ }^{11}$ Medical Department, TEVA Pharmaceutical Ltd., Calle de Anabel Segura, 11, 28108 Alcobendas, Spain

*Corresponding author: Rainel Sánchez-de la Rosa, Medical Department, TEVA Pharmaceutical Ltd., Calle de Anabel Segura, 11, 28108 Alcobendas, Spain, Tel: +34 913542621; Fax: +34 915330472; E-mail: rainel.sanchez@tevaes.com

Received Date: Dec 11, 2013, Accepted Date: Mar 11, 2014, Published Date: Mar 17, 2014

Copyright: (c) 2014 Olascoaga-Urtaza J, et al. This is an open-access article distributed under the terms of the Creative Commons Attribution License, which permits unrestricted use, distribution, and reproduction in any medium, provided the original author and source are credited.

\section{Abstract}

Introduction: Quality of life (QoL) has gained increasing importance in multiple sclerosis (MS). We aimed to assess QoL and potentially associated factors such as depression, sexual dysfunction and work absenteeism in patients starting glatiramer acetate (GA) in clinical practice.

Methods: A prospective cohort study carried out in relapsing-remitting MS patients starting GA as first-line treatment. Patient information on QoL (Multiple Sclerosis Quality of Life-54 [MSQoL-54]), depression (Beck Depression Inventory), sexual dysfunction (Multiple Sclerosis Intimacy and Sexuality Questionnaire-19) and work absenteeism was assessed from starting GA to week 96 .

Results: Ninety-eight evaluable patients were enrolled in the study (mean age, $38.0 \pm 8.4$ years; female, $69.4 \%$; mean MS duration, $42.6 \pm 62.9$ months; annual relapse rate since MS diagnosis, 0.4 ), and followed up at weeks 24 $(n=96), 48(n=94), 72(n=89)$ and $96(n=80)$. Patient QoL was preserved during the study, with improvements on the MSQoL-54 subscales of change in health $(p<0.05)$ and health distress $(p<0.05)$. Depression, primary and secondary sexual dysfunction remained stable, but the number of patients with tertiary sexual dysfunction decreased at week $96(p<0.05)$. Work absenteeism also decreased over the study $(p<0.01)$. Depression, sexual dysfunction and work absenteeism affected MSQoL-54 physical and mental health composites $(p<0.05)$.

Conclusion: QoL of our patients was preserved during the 96-week administration of GA. Though depression, sexual dysfunction and work absenteeism impair patient QoL, they remained stable or even improved during the study.

Keywords: Absenteeism; Depression; Glatiramer acetate; Quality of life; Multiple sclerosis; Sexual dysfunction

\section{Introduction}

Quality of life assessment in patients with multiple sclerosis has gained increasing importance as it encompasses all aspects of patients' lives that may be affected by the disease. Though patients' quality of life worsens as multiple sclerosis progresses and physical function deteriorates, it depends not only on the disability caused by physical limitations but also on their emotional status, which may also affect the perception of wellbeing and quality of life [1-3]. In this scenario, depression has been shown to have a notable impact on quality of life, and is considered a significant and independent predictor of impaired quality of life [4-10]. Sexual dysfunction is another common and often underestimated clinical symptom of multiple sclerosis that, along with its emotional repercussions, has been shown to affect patients' quality of life $[11,12]$. The information available on the impact of sexual dysfunction on quality of life, however, is still limited. The consequences of multiple sclerosis often negatively affect patients' 
Citation: Olascoaga-Urtaza J, Meca-Lallana V, Hernández-Clares R, Ramió-Torrentà L, Pérez D, et al. (2014) Quality of Life, Depression, Sexual Dysfunction and Work Absenteeism in Relapsing-Remitting Multiple Sclerosis Patients Starting Glatiramer Acetate as First-Line Treatment: A Prospective Cohort Study. J Neurol Neurophysiol 5: 199. doi:10.4172/2155-9562.1000199

Page 2 of 9

working life and may even lead to permanent unemployment [2]. This unemployment represents one of the factors that most modifies patients' way of living as a result of its influence on their usual activities or interests and its impact on increasing emotional distress [2], while sustaining employment has been shown to be associated with improved quality of life $[13,14]$.

First-line disease-modifying drugs for relapsing-remitting multiple sclerosis including interferon-beta (INFb)- $1 \mathrm{a}$, INFb-1b and glatiramer acetate have been shown to improve the course of the disease. However, their effect on patients' quality of life has not yet been fully clarified. Indeed, the information available on INFb's effect on quality of life is controversial, ranging from some benefit [15] to absence of effect [16-19] or even to quality of life detriment [20]. The effect of glatiramer acetate treatment on quality of life has not been well assessed, and improvements in quality of life have been reported in treatment-naïve patients with relapsing-remitting multiple sclerosis six months after starting GA treatment that were sustained for another six months [21].

In light of the above, this study aimed to expand the information available on quality of life and potentially associated factors such as depression, sexual dysfunction and work absenteeism in patients with relapsing-remitting multiple sclerosis starting glatiramer acetate as first-line treatment in clinical practice.

\section{Materials and Methods}

This study was conducted in the Departments of Neurology at 37 Spanish hospitals in accordance with the World Medical Association Declaration of Helsinki, all its amendments and national regulations. The study was approved by the ethic committee of Hospital Donostia (San Sebastián, Spain) and all patients gave their written informed consent.

\section{Patient population}

Between November 2009 and November 2010, all patients meeting selection criteria who agreed to participate in the study were consecutively recruited into the study. Inclusion criteria were patients aged 18 to 60 years, with a diagnosis of relapsing-remitting multiple sclerosis, no previous treatment for multiple sclerosis and a score of 5.5 or less on the Expanded Disability Status Scale (EDSS). Patients were to start glatiramer acetate (Copaxone ${ }^{\bullet}$, Teva Pharmaceuticals Ltd., London, United Kingdom) for multiple sclerosis treatment and must not have had any cognitive impairment that precluded understanding of the patient's information sheet and informed consent form.

\section{Study design}

This was a prospective cohort study conducted in patients with relapsing-remitting multiple sclerosis receiving glatiramer acetate treatment for multiple sclerosis and followed-up for two years according to clinical practice.

All treatments were administered from commercial sources and according to routine clinical practice. No restrictions regarding patients' treatment were specified in the study protocol.

\section{Assessments}

Patients' information was retrieved from their medical charts at the start of glatiramer acetate treatment (baseline) and at weeks 24, 48, 72 and 96. The data retrieved at these visits included demographics, medical history of multiple sclerosis, patients' disability according to the EDSS [22], quality of life measured according to scores on the Multiple Sclerosis Quality of Live-54 (MSQoL-54) questionnaire $[23,24]$, depression according to scores on the 21-item Beck Depression Inventory (BDI) $[25,26]$, sexual disfunction according to the Multiple Sclerosis Intimacy and Sexuality Questionnaire-19 (MSISQ-19), [27,28] and work absenteeism related to multiple sclerosis according to the occurrence of work absenteeism, the number of working days missed and the causes of work absenteeism.

EDSS scores, which range from 0 (normal neurological status) to 10 (death from multiple sclerosis), were obtained by the same researcher in a given patient. The MSQoL-54 questionnaire consists of 54 items distributed in 12 multiple-item scales and two single-item scales, including questions from the Short Form 36-Item Health Survey as a generic core measure and 18 additional items specific for multiple sclerosis that assess health distress, sexual function, overall quality of life, cognitive function and energy. Physical and mental health composite scores are calculated as a simplified two-dimension solution to MSQoL-54 questionnaire. The composites scores range from 0 (poor health) to 100 (optimal health). The BDI is composed of 21 categories of symptoms and attitudes which describe a specific behavioral manifestation of depression and consist of a graded series of four to five self-evaluative statements. Numerical values are assigned for each statement from 0 (neutral) to 3 (maximal severity) indicating the degree of severity of the manifestations of depression. Total scores range from 0 to 63 , where higher scores indicate worse depressive states. Patients may also be categorized as having ups and downs considered normal if their BDI scores were 10 or less, as having mild mood disturbance if their BDI scores were between 11 and 16, as having borderline clinical depression if their BDI scores were between 17 and 20, as having moderate depression if their BDI scores were between 21 and 30, as having severe depression if their BDI scores were between 31 and 40 and as having extreme depression if their BDI scores were higher than 40 . The cut-off value of at least 17 points was established as suggestive of the presence of depression. The MSISQ-19 consists of 19 items assessing the perceived influence of multiple sclerosis symptoms on sexual activity and satisfaction. Scores on the MSISQ-19 show the presence of primary, secondary and tertiary sexual dysfunction. Primary sexual dysfunction occurs as a result of neurologic changes related to multiple sclerosis that directly affect sexual feelings and/or sexual response, secondary sexual dysfunction refers to physical changes related to multiple sclerosis that affect the sexual response indirectly and tertiary sexual dysfunction refers to psychological, emotional, social and cultural aspects of multiple sclerosis that impact upon sexuality.

\section{Statistical considerations}

The primary efficacy endpoint was the change in patients' quality of life during the 96-week study period, measured according to scores on the physical and mental health composites of the MSQoL-54 questionnaire. Sample size was calculated to fulfill the primary objective of the study. At the time of study design, the only data available on the impact of multiple sclerosis therapy on quality of life measured by the MSQoL-54 questionnaire was reported by Simone et al., who found that multiple sclerosis patients followed up for two 
Citation: Olascoaga-Urtaza J, Meca-Lallana V, Hernández-Clares R, Ramió-Torrentà L, Pérez D, et al. (2014) Quality of Life, Depression, Sexual Dysfunction and Work Absenteeism in Relapsing-Remitting Multiple Sclerosis Patients Starting Glatiramer Acetate as First-Line Treatment: A Prospective Cohort Study. J Neurol Neurophysiol 5: 199. doi:10.4172/2155-9562.1000199

Page 3 of 9

years experienced a decrease of six or more points in $80 \%$ of MSQoL-45 measurements (dimensions and summary composite scores), with an standard deviation of approximately 20 points [20]. Taking into account these data, an alpha risk of 0.05 and a beta risk of 0.20 in a two-sided analysis, the number of evaluable patients needed to be enrolled into the study to detect a difference of six or more points in MSQoL-54 scores would be of 92 patients; considering a percentage of missing data of $20 \%$ or lower, e.g. due to non-evaluable patients, the total sample size would be of 110 patients. Analysis of the primary endpoint included the calculation of mean scores and standard deviations (SD) of both physical and mental health composites of MSQoL-54 questionnaire throughout the study. Comparison of these scores during the study was performed using the repeated measures general linear model. Comparison of scores on the MSQoL-54 questionnaire at baseline with those reported at week 24, 48, 72 and 96 were also performed using paired t-tests.

The secondary endpoints included assessment of depression, sexual dysfunction and work absenteeism at baseline. Other secondary endpoints were the change in depression, sexual dysfunction and work absenteeism during the study and their impact on patients' quality of life.

The distribution of patients according to the following categories of the BDI was calculated as the frequency and valid percentage in each study visit: ups and downs considered normal (BDI scores, $\leq 10$ ), mild mood disturbance (BDI scores, 11-16), borderline clinical depression (BDI scores, 17-20), moderate depression (BDI scores, 21-30), severe depression (BDI scores, 31-40) and extreme depression (BDI scores, $>40$ ). The overall frequency of patients with depression, which was defined as a BDI score $\geq 17$, was also calculated. Comparison of mean BDI scores and the proportion of patients within the above categories during the study was performed using paired t-tests and McNemar's tests, respectively. The impact of depression on patients' quality of life was assessed comparing the scores on the physical and mental health composites of MSQoL-54 questionnaire reported by patients with those without depression using t-tests or Mann-Whitney tests.

The frequencies and valid percentages of patients with primary, secondary and tertiary sexual dysfunction according to MSISQ-19 scores were calculated in each study visit. The overall frequency of sexual dysfunction in each study visit was also assessed according to patients with at least one of these categories (primary, secondary or tertiary sexual dysfunction). Changes during the study were assessed using McNemar's tests. The impact of sexual dysfunction on patients' quality of life was assessed comparing the scores on the physical and mental health composites of MSQoL-54 questionnaire between patients without sexual dysfunction and those with any kind of sexual dysfunction by using Mann-Whitney tests.

Work absenteeism related to multiple sclerosis was assessed according to the frequency and valid percentage of patients missing at least one day from work, the mean (SD) number of working days missed and the causes for work absenteeism. Changes in the frequency of patients absent from work and the number of working days missed during the study were assessed using McNemar's tests and Wilcoxon tests, respectively. The impact of work absenteeism on patients' quality of life was assessed by comparing the scores on the physical and mental health composites of the MSQoL-54 questionnaire in patients at least one day absent from work versus those with no day absent from work using Mann-Whitney tests.
A correction method for multiple testing was not performed in the statistical analysis for the present study due to the controversy about its use in observational studies leading to potential risks and errors $[29,30]$. Further information on this subject is provided in Appendix 1.

Missing data were not considered in the analyses and a significance level of 0.05 was used for statistical testing. The statistical analyses were performed with the Statistical Package for the Social Sciences (SPSS) version 17.0 (SPSS Inc., Chicago, Illinois, USA).

\section{Results}

\section{Patient characteristics}

A total of 101 patients agreed to participate in the study, three of whom were excluded from the analysis due to insufficient available data. Therefore, the evaluable population comprised a total of 98 patients, whose characteristics are described in Table 1. Patients' disposition during the study is shown in Figure 1.

\begin{tabular}{|c|c|}
\hline Patient characteristics & Value \\
\hline \multicolumn{2}{|l|}{ Mean age, years $(S D)$ : } \\
\hline At baseline & $38.0(8.4)$ \\
\hline At first relapse* & $32.2(8.0)$ \\
\hline Female, n (\%) & $68(69.4)$ \\
\hline \multicolumn{2}{|l|}{ Ethnicity, n (\%): } \\
\hline Caucasian & $96(98.0)$ \\
\hline Other & $2(2.0)$ \\
\hline Family history of multiple sclerosis, $\mathrm{n}(\%)^{\dagger}$ & $10(10.4)$ \\
\hline Mean duration of multiple sclerosis, months $(\mathrm{SD})^{\ddagger}$ & $42.6(62.9)$ \\
\hline $\begin{array}{l}\text { Mean number of relapses since multiple sclerosis } \\
\text { diagnosis (SD) }\end{array}$ & $1.3(1.3)$ \\
\hline Annual relapse rate since multiple sclerosis diagnosis & 0.4 \\
\hline Mean time from last relapse to baseline, months $(S D)^{\S}$ & $14.8(23.8)$ \\
\hline
\end{tabular}

Table 1: Baseline patient characteristics $(\mathrm{N}=98)$.

\section{Expanded disability status scale}

Patients showed a mean (SD) EDSS score of 1.8 (1.0) at baseline, with $88(89.8 \%)$ patients showing minimal disability (EDSS $0-2.5)$ and $10(10.2 \%)$ patients showing moderate disability (EDSS 3-5) without technical aid. EDSS scores during the study period are described in Figure 2 . 
Citation: Olascoaga-Urtaza J, Meca-Lallana V, Hernández-Clares R, Ramió-Torrentà L, Pérez D, et al. (2014) Quality of Life, Depression, Sexual Dysfunction and Work Absenteeism in Relapsing-Remitting Multiple Sclerosis Patients Starting Glatiramer Acetate as First-Line Treatment: A Prospective Cohort Study. J Neurol Neurophysiol 5: 199. doi:10.4172/2155-9562.1000199

Page 4 of 9

\begin{tabular}{|c|c|}
\hline $\begin{array}{l}\text { Patients recruited } \\
\qquad N=101\end{array}$ & \multirow[b]{2}{*}{$\begin{array}{l}\text { Nonevaluable }(n=3) \text { : } \\
\text { - Insuficient data available, } n=3\end{array}$} \\
\hline & \\
\hline $\begin{array}{l}\text { Evaluable patients } \\
\qquad N=98\end{array}$ & \multirow{4}{*}{$\begin{array}{l}\text { Early discontinuation }(n=16) \text { : } \\
\text { - Change of multiple sclerosis } \\
\text { treatment, } n=5 \\
\text { - Patient's decision, } n=3 \\
\text { - Investigator's decision, } n=2 \\
\text { - Lost to follow-up, } n=2 \\
\text { - Patient's negative to fill in } \\
\text { study questionnaires, } n=2 \\
\text { - Patient's travelling abroad, } n=1 \\
\text { - Patient's death, } n=1 \\
\text { Nonevaluable for week } 96(n=2) \text { : } \\
\text { - Lack of data available, } n=2\end{array}$} \\
\hline & \\
\hline $\begin{array}{l}\text { Data available for } \\
\text { analysis: } \\
\text { - Baseline, } n=98 \\
\text { - Week 24, n=96 } \\
\text { - Week 48, n=94 } \\
\text { - Week 72, n=89 } \\
\text { - Week 96, n=80 }\end{array}$ & \\
\hline & \\
\hline
\end{tabular}

Figure 1: Summary of patient disposition.

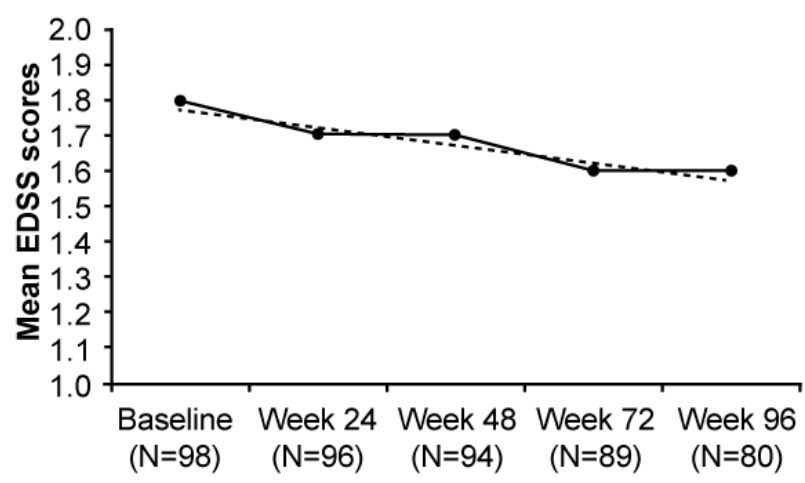

Figure 2: Mean scores on the Expanded Disability Status Scale. Dotted line represents the trend line for mean scores on the Expanded Disability Status Scale throughout the study period. EDSS: Expanded Disability Status Scale.

When paired comparisons were performed to assess differences in EDSS scores from baseline, it was shown that the mean EDSS scores remained stable throughout the study period but with a slight tendency to improvement at week 96 (mean [SD], 1.1 [0.3] versus 1.0 [0.2], $\mathrm{p}=0.058$ ). In addition, the proportion of patients with minimal disability slightly increased and the proportion of patients with moderate disability that did not need any technical aid slightly decreased, though not significantly, reaching $95.0 \%(\mathrm{n}=76)$ and $5.0 \%$ $(n=4)$ of patients, respectively, at week 96.

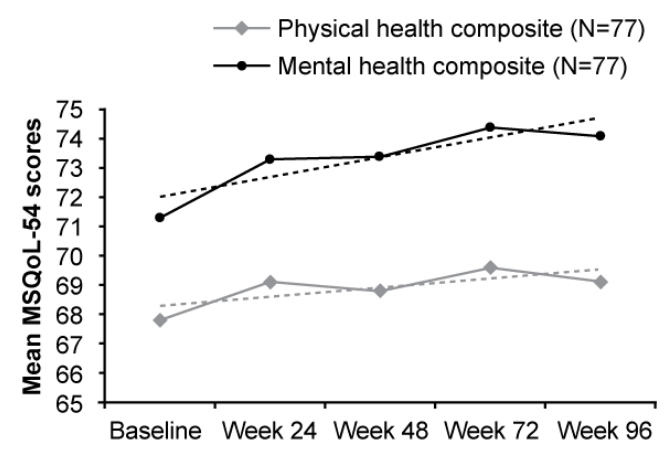

Figure 3: Mean scores on physical and mental health composites of Multiple Sclerosis Quality of Life-54 questionnaire. Dotted lines represent trend lines for mean scores on physical and mental health composites throughout the study period. MSQoL-54: Multiple Sclerosis Quality of Life- 54 .

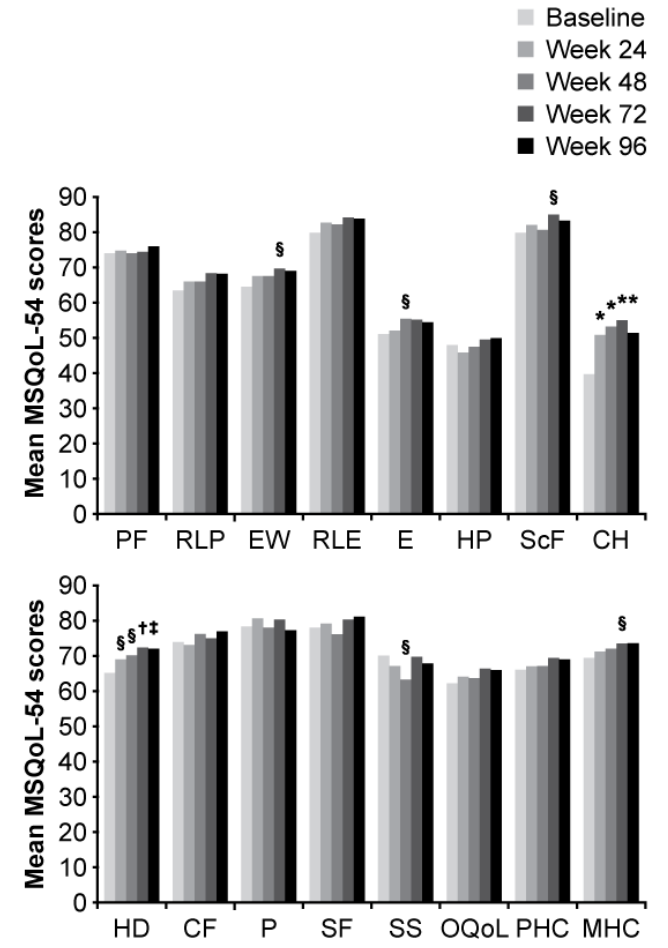

Figure 4: Mean scores on Multiple Sclerosis Quality of Life-54 subscales. ${ }^{*} \mathrm{p}<0.001$ versus baseline; $\dagger \mathrm{p}<0.005$ versus baseline; $\ddagger \mathrm{p}<0.01$ versus baseline; $\$ \mathrm{p}<0.05$ versus baseline. CF: cognitive function; $\mathrm{CH}$ : change in health; E: energy; EW: emotional wellbeing; HD: health distress; HP: health perception; MHC: mental health composite; OQoL: overall quality of life; P: pain; PF: physical function; PHC: physical health composite; RLE: role limitation-emotional; RLP: role limitation-physical; ScF: social function; SF: sexual function; SS: sexual satisfaction. 
Citation: Olascoaga-Urtaza J, Meca-Lallana V, Hernández-Clares R, Ramió-Torrentà L, Pérez D, et al. (2014) Quality of Life, Depression, Sexual Dysfunction and Work Absenteeism in Relapsing-Remitting Multiple Sclerosis Patients Starting Glatiramer Acetate as First-Line Treatment: A Prospective Cohort Study. J Neurol Neurophysiol 5: 199. doi:10.4172/2155-9562.1000199

Page 5 of 9

\section{Multiple sclerosis quality of life-54}

Even though scores on the MSQoL-54 questionnaire improved slightly during the 96-week study period, the results obtained from the repeated measures general linear model showed that statistically significant differences were not attained in either the physical or mental health composites (Figure 3). Similarly, comparison of scores on the physical and mental health composites between baseline and weeks 24, 48, 72 and 96 only showed statistically significant differences in the mental health composite at week 72 , in which the scores were significantly higher than baseline (mean [SD], 70.6 [15.3] versus 73.9 [15.9], $\mathrm{p}<0.05$; Figure 4). In addition, consistent statistically significant improvements from baseline to weeks $24,48,72$ and 96 were observed in the MSQoL-54 subscales of change in health and health distress (Figure 4).

\section{Depression}

A total of $65(66.3 \%)$ patients reported experiencing ups and downs considered normal according to the BDI at baseline, while $20(20.4 \%)$ patients showed mild mood disturbance, $10(10.2 \%)$ borderline clinical depression and $3(3.1 \%)$ patients moderate depression. Therefore, a total of $13(13.3 \%)$ patients showed overall depression (Table 2). No significant differences were found in either the mean BDI scores or the distribution of patients among the BDI categories throughout the study.

\begin{tabular}{|c|c|c|c|c|c|}
\hline & Baseline & Week 24 & Week 48 & $\begin{array}{l}\text { Week } \\
72\end{array}$ & Week 96 \\
\hline & $(\mathrm{N}=98)$ & $(\mathrm{N}=96)$ & $(\mathrm{N}=94)$ & $(\mathrm{N}=89)$ & $(\mathrm{N}=80)$ \\
\hline \multicolumn{6}{|l|}{$\begin{array}{l}\text { Depression } \\
\text { (BDI): }{ }^{*}, t\end{array}$} \\
\hline \multicolumn{6}{|l|}{$\begin{array}{l}\text { Depression } \\
\text { categories, n (\%): }\end{array}$} \\
\hline $\begin{array}{l}\text { Ups and downs } \\
\text { considered normal } \\
\text { (BDI scores 1-10) }\end{array}$ & $65(66.3)$ & $64(66.7)$ & $61(67.0)$ & $\begin{array}{l}70 \\
(80.5)\end{array}$ & $63(78.8)$ \\
\hline 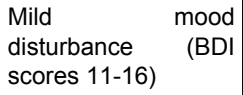 & $20(20.4)$ & $19(19.8)$ & $18(19.8)$ & $6(6.9)$ & $7(8.8)$ \\
\hline $\begin{array}{lr}\text { Borderline } & \text { clinical } \\
\text { depression } & \text { (BDI } \\
\text { scores 17-20) } & \end{array}$ & $10(10.2)$ & $6(6.3)$ & $5(5.5)$ & $4(4.6)$ & $7(8.8)$ \\
\hline $\begin{array}{l}\text { Moderate } \\
\text { depression } \\
\text { scores 21-30) }\end{array}$ & $3(3.1)$ & $6(6.3)$ & $5(5.5)$ & $7(8.0)$ & $3(3.8)$ \\
\hline $\begin{array}{l}\text { Severe depression } \\
\text { (BDI scores } 31-40 \text { ) }\end{array}$ & $0(0.0)$ & $1(1.0)$ & $2(2.2)$ & $0(0.0)$ & $0(0.0)$ \\
\hline $\begin{array}{l}\text { Extreme depression } \\
(\text { BDI scores }>40)\end{array}$ & $0(0.0)$ & $0(0.0)$ & $0(0.0)$ & $0(0.0)$ & $0(0.0)$ \\
\hline $\begin{array}{l}\text { Overall depression } \\
\text { (BDI scores } \geq 17), n \\
(\%)\end{array}$ & $13(13.3)$ & $13(13.5)$ & $12(13.2)$ & $\begin{array}{l}11 \\
(12.6)\end{array}$ & $10(12.5)$ \\
\hline $\begin{array}{l}\text { Mean } \\
\text { (SD) }\end{array}$ & $8.8(6.3)$ & $8.5(7.1)$ & $8.5(7.4)$ & $\begin{array}{l}7.6 \\
(6.7)\end{array}$ & $7.4(6.1)$ \\
\hline $\begin{array}{l}\text { Sexual dysfunction } \\
\text { (MSISQ-19), n (\%): } \\
\S, \|\end{array}$ & & & & & \\
\hline
\end{tabular}

\begin{tabular}{|c|c|c|c|c|c|}
\hline $\begin{array}{l}\text { Primary sexual } \\
\text { dysfunction** }\end{array}$ & $31(32.6)$ & $27(29.0)$ & $27(30.7)$ & $\begin{array}{l}21 \\
(25.3)\end{array}$ & $23(30.7)$ \\
\hline $\begin{array}{l}\text { Secondary sexual } \\
\text { dysfunction }{ }^{* *}\end{array}$ & $21(22.1)$ & $17(18.3)$ & $15(17.0)$ & $\begin{array}{l}12 \\
(14.5)\end{array}$ & $18(24.0)$ \\
\hline $\begin{array}{l}\text { Tertiary sexual } \\
\text { dysfunction }\end{array}$ & $17(17.9)$ & $11(11.8)$ & $13(14.8)$ & $7(8.4)$ & $4(5.3)$ \\
\hline $\begin{array}{ll}\begin{array}{l}\text { Overall } \\
\text { dysfunction }\end{array} & \text { sexual }\end{array}$ & $43(45.3)$ & $36(38.7)$ & $34(38.6)$ & $\begin{array}{l}27 \\
(32.5)\end{array}$ & $31(41.3)$ \\
\hline \multicolumn{6}{|l|}{ Work absenteeism: } \\
\hline $\begin{array}{l}\text { Patients missing at } \\
\text { least one day from } \\
\text { work, } \\
(\%): t+, \ddagger+\S \S, \| \text { IIII }\end{array}$ & $46(52.9)$ & $27(30.3)$ & $19(22.9)$ & $\begin{array}{l}22 \\
(26.5)\end{array}$ & $18(25.4)$ \\
\hline $\begin{array}{l}\text { Mean number of } \\
\text { working days missed } \\
(\mathrm{SD})^{* \star *}, \mathrm{t+},{ }^{*}, \dagger\end{array}$ & $\begin{array}{l}45.8 \\
(56.5)\end{array}$ & $\begin{array}{l}40.6 \\
(63.5)\end{array}$ & $\begin{array}{l}21.6 \\
(44.9)\end{array}$ & $\begin{array}{l}42.3 \\
(51.7)\end{array}$ & $38.9(66.1)$ \\
\hline \multicolumn{6}{|l|}{$\begin{array}{lr}\text { Causes for } & \text { work } \\
\text { absenteeism, } & n \\
(\%): \sharp \neq \ddagger & \end{array}$} \\
\hline $\begin{array}{l}\text { Multiple sclerosis } \\
\text { signs }\end{array}$ & $26(56.5)$ & $15(55.6)$ & $10(52.6)$ & $\begin{array}{l}12 \\
(54.5)\end{array}$ & $12(66.7)$ \\
\hline Disease relapse & $16(34.8)$ & $8(29.6)$ & $3(15.8)$ & $\begin{array}{l}6 \\
(27.3)\end{array}$ & $5(27.8)$ \\
\hline Other & $11(23.9)$ & $5(18.5)$ & $8(42.1)$ & $\begin{array}{l}7 \\
(31.8)\end{array}$ & $1(5.6)$ \\
\hline
\end{tabular}

Table 2: Patients' depression, sexual dysfunction and work absenteeism throughout the 96-week study period.

${ }^{*}$ Missing data at week $48, \mathrm{n}=3$; ${ }^{\dagger}$ Missing data at week $72, \mathrm{n}=2$; ${ }^{\ddagger}$ Missing data at baseline and week 24, $\mathrm{n}=3$; ${ }^{\circledR}$ Missing data at weeks 48 and $72, n=6$; "Missing data at week $96, n=5$; ${ }^{* *}$ One patient may be included in more than one of the following categories: primary sexual dysfunction, secondary sexual dysfunction and tertiary sexual dysfunction; ${ }^{\dagger}$ Missing data at baseline and week $48, n=11$; ${ }^{\ddagger}$ Missing data at week 24, $\mathrm{n}=7 ;{ }^{\S \S}$ Missing data at week $72, \mathrm{n}=6$; ${ }^{\||| \mid}$Missing data at week $96, \mathrm{n}=9 ;{ }^{* * *}$ Missing data at baseline, $\mathrm{n}=3 ;{ }^{\dagger \dagger}$ Missing data at week

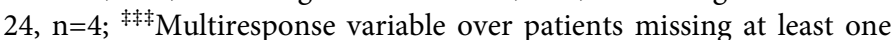
day from work.

BDI: Beck's Depression Inventory; MSISQ-19: Multiple Sclerosis Intimacy and Sexuality Questionnaire-19; SD: standard deviation.

The analysis of the impact of depression on patients' quality of life showed that patients with depression reported worse scores on both physical and mental health composites of the MSQoL-54 questionnaire throughout the study period (Figure 5a).

\section{Multiple sclerosis intimacy and sexuality questionnaire-19}

The overall frequency of patients with baseline sexual dysfunction according to MSISQ-19 scores reached 43 (45.3\%) patients, and remained stable throughout the 96 -week study period.

When the type of sexual dysfunction according to MSISQ-19 was analyzed at baseline, primary sexual dysfunction was found in 31 (32.6\%) patients, secondary sexual dysfunction in 21 (22.1\%) patients and tertiary sexual dysfunction in $17(17.9 \%)$ patients (Table 2). Distribution of patients with primary and secondary sexual 
Citation: Olascoaga-Urtaza J, Meca-Lallana V, Hernández-Clares R, Ramió-Torrentà L, Pérez D, et al. (2014) Quality of Life, Depression, Sexual Dysfunction and Work Absenteeism in Relapsing-Remitting Multiple Sclerosis Patients Starting Glatiramer Acetate as First-Line Treatment: A Prospective Cohort Study. J Neurol Neurophysiol 5: 199. doi:10.4172/2155-9562.1000199

Page 6 of 9

dysfunction did not significantly change from baseline to weeks 24,48 , 72 or 96 . However, the proportion of patients with tertiary sexual dysfunction tended to decrease from baseline to week $72(\mathrm{p}=0.057)$, reaching statistically significance at week $96(\mathrm{p}<0.05)$.

The presence of sexual dysfunction was shown to worsen patients' quality of life, as patients with sexual dysfunction reported lower scores on the physical and mental health composites of the MSQoL-54 questionnaire during the whole study period (Figure 5b).

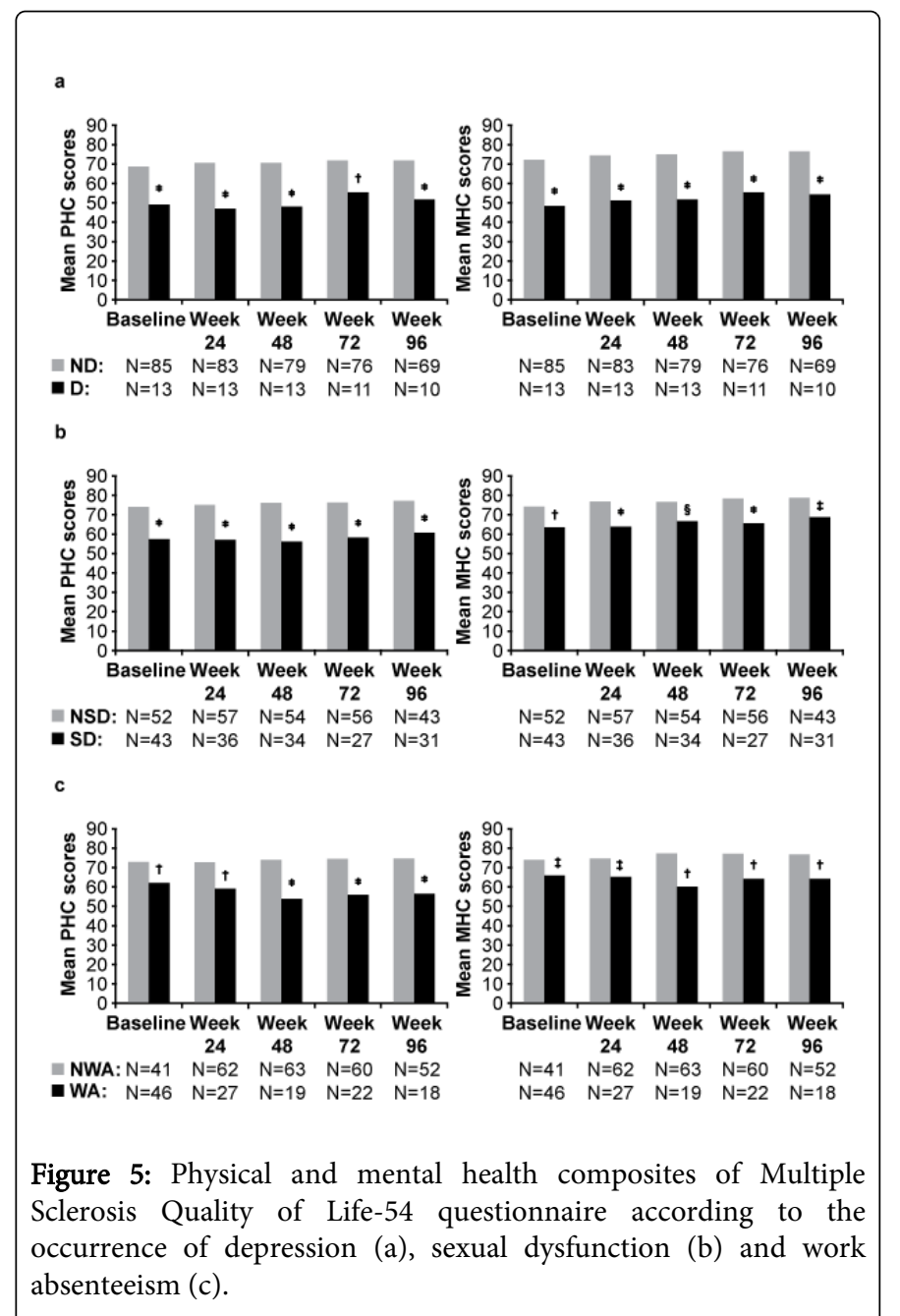

${ }^{*} \mathrm{p}<0.001 ; \uparrow \mathrm{p}<0.005 ; \ddagger \mathrm{p}<0.01 ; \S \mathrm{p}<0.05$. D: depression; MHC: mental health composite; ND: no depression; NSD: no sexual dysfunction; NWA: no work absenteeism; PHC: physical health composite; SD: sexual dysfunction; WA: work absenteeism.

\section{Work absenteeism}

At baseline, 46 (52.9\%) patients reported having missed at least one day from work in the previous six months due to multiple sclerosis. The mean (SD) number of working days missed was 45.8 (56.5) days and the main reasons for work absenteeism were clinical signs of multiple sclerosis and disease relapses (Table 2). When work absenteeism was analyzed over the whole study, statistically significant decreases from baseline were observed in the proportion of patients missing at least one day from work at week $24(\mathrm{p}<0.01)$, week 48 $(\mathrm{p}<0.001)$, week $72(\mathrm{p}<0.01)$ and week $96(\mathrm{p}<0.01)$. Even though the number of working days missed from work decreased from baseline, statistically significant differences were only reached at week 48 $(\mathrm{p}<0.05)$

Work absenteeism was associated with patients' quality of life during the 96-week study period, as patients absent from work reported worse scores on both the physical and mental health composites of the MSQoL-54 questionnaire at baseline, week 24, week 48, week 72 and week 96 (Figure 5c).

\section{Discussion}

This prospective cohort study showed that the quality of life of our population of patients with relapsing-remitting multiple sclerosis was preserved during the 96-week administration of glatiramer acetate under clinical practice conditions. Although glatiramer acetate treatment may have played a role in slowing down worsening of multiple sclerosis, this finding must be considered with caution since our patient population had intrinsically low disease activity in terms of EDSS scores and annual relapse rate. However, other studies also showed low disease activity in patients treated under clinical practice conditions [31,32], and another reported early gain in quality of life measured by the Leeds Multiple Sclerosis Quality of Life scale in patients receiving glatiramer acetate in daily practice [21].

A protective effect on quality of life of other first-line treatments for multiple sclerosis such as IFNb has also been previously suggested in patients with relapsing-remitting multiple sclerosis[18], whose quality of life measured by the MSQoL-54, Short Form 36-Item Health Survey and Functional Assessment of Multiple Sclerosis questionnaires remained stable for up to three years [16-18]. However, though some improvements in the physical health composite of the MSQoL-54 questionnaire have been reported after two years of treatment with IFNb [15], detriments in patients' quality of life have also been reported during the same duration of IFNb treatment, mainly as a result of worsening of the mental health composite [20].

In our study, disability, depression, primary sexual dysfunction and secondary sexual dysfunction were observed to remain stable during the study period, while tertiary sexual dysfunction and work absenteeism due to multiple sclerosis were significantly improved at week 96. Maintenance of disability even during 15 years of glatiramer acetate administration has been previously reported, showing a mean EDSS change of 0.6 points from the start of treatment [33]. However, since the EDSS is highly dependent on ambulation and does not provide information on parameters associated with patients' wellbeing [34], other parameters that might be potentially associated with patients' wellbeing needed to be assessed. Indeed, our results support the influence of depression, sexual dysfunction and work absenteeism on the quality of life of patients with relapsing remitting-multiple sclerosis. These results are in line with previous studies reporting that multiple sclerosis patients with lifetime major depression show lower quality of life measured by the MSQoL-54 questionnaire, mainly in terms of energy, mental health, cognitive function, general quality of life, sexual function and emotional role limitations [9]. Depression measured according to the BDI or the Hamilton Rating Scale for Depression has been reported to be associated with both physical and mental health composites of the MSQoL-54 questionnaire [4-7], regardless of the disease-related physical disability and disease type [7]. Depression has been claimed to be a significant independent predictor of impaired patient quality of life measured using the MSQoL-54 and 
Citation: Olascoaga-Urtaza J, Meca-Lallana V, Hernández-Clares R, Ramió-Torrentà L, Pérez D, et al. (2014) Quality of Life, Depression, Sexual Dysfunction and Work Absenteeism in Relapsing-Remitting Multiple Sclerosis Patients Starting Glatiramer Acetate as First-Line Treatment: A Prospective Cohort Study. J Neurol Neurophysiol 5: 199. doi:10.4172/2155-9562.1000199

Page 7 of 9

Functional Assessment of Multiple Sclerosis questionnaires [4-10]. Patients with sexual dysfunction have also been shown to have poorer quality of life, with significantly lower scores on all scales of the Short Form 36-Item Health Survey [11] and on all of scales of the MSQoL-54 questionnaire except for pain and cognitive function [12]. Similar detriments in quality of life were observed in unemployed versus unemployed patients, who had lower scores on most dimensions of the MSQoL-54 questionnaire [13,14], suggesting the importance of sustained employment after the diagnosis of multiple sclerosis [14].

Though the low disease activity of our study patient population does not allow conclusions to be drawn about the effect of glatiramer acetate, decreased work absenteeism has previously been reported in patients receiving this agent $[35,36]$. In addition, there is no evidence that glatiramer acetate aggravates depression and it might even induce an antidepressant effect through its neuroprotective and antiinflammatory activity [37]. Indeed, switching to glatiramer acetate has been recommended when a depressive episode is confirmed in patients receiving INFb [38]. Moreover, recently published data on patients switching from IFNb to glatiramer acetate [39], and preliminary results from ongoing studies in patients switching to glatiramer acetate $[40,41]$ showed patients' quality of life remained stable or even improved.

The authors acknowledge that although observational studies provide valuable information on treatments administered in clinical practice, their limitations should be considered when interpreting the results. The open-label study design, the absence of a comparator group and the potential regression to the mean effect should also be taken into account. In addition, data on other factors that might have influenced patients' quality of life such as relapses, fatigue and treatment-related adverse events were not retrieved, and longer follow-up might have been needed for potential differences to become evident. The low disease activity of the study patient population precluded drawing conclusions about the effect of glatiramer acetate and may limit the representativeness of the study findings. Though caution is advisable when interpreting the study results, we consider that they still provide helpful information to physicians when treating multiple sclerosis in clinical practice.

In conclusion, the study results show that the quality of life of our population of patients with relapsing-remitting multiple sclerosis was preserved during the 96-week administration of glatiramer acetate in clinical practice conditions. Depression, sexual dysfunction and work absenteeism due to multiple sclerosis are factors that significantly impair patients' quality of life. However, our study shows stable disability, depression and primary/secondary sexual dysfunction as well as improved tertiary sexual dysfunction and work absenteeism. The study findings should be interpreted with caution based on the low disease activity of the patient population. Further research is still needed to confirm the effect of glatiramer acetate, and to increase knowledge of other potentially associated factors, the long-term effect of multiple sclerosis therapies and the impact of the switch to glatiramer acetate on patients' quality of life.

\section{Appendix 1}

There is currently no unanimity about the use of multiple test corrections (methods such as those of Bonferroni, Holm, Benjamini, etc.). In general, these methods reduce the probability of making type I errors, but they increase the probability of making type II errors.
It seems cautious to prioritize minimizing the probability of type I errors over type II errors in studies where: several treatments are compared, probabilistic independence is expected between analysis groups and/or variables that would give rise to multiple tests, results have confirmatory implications for practical use.

Methods of correcting for multiple testing provide solutions for these situations. However, if any of the above conditions are not a priority or are not applicable to the study, it would be cautious to minimize the probability of making a type II error rather than a type I error.

Using multiple test corrections would minimize type I errors, but it would also increase the probability of type II errors, which would imply that differences that are really related to the phenomena under study would not be detected.

In the present study, the effect of only one treatment was assessed during the study follow-up, and its use was supported by certain evidence of effectiveness. Therefore, it appears reasonable to assume the overall absence of probabilistic independence in the measurements of variables of patients included in the study. Consequently, the authors decided to prioritize the avoidance of increasing the probability of committing type II errors.

For readers who may be interested in the effect of multiple test corrections, Bonferroni correction would result in a p-value that was estimated to be of 0.0003 for the analyses carried out in this study. The authors would also like to explain that significant p-values of the study analyses were classified to be shown in the article as $\mathrm{p}<0.05, \mathrm{p}<0.01$, $\mathrm{p}<0.005$ or $\mathrm{p}<0.001$. The data included in this appendix is intended to provide the reader interested in knowing more about multiple test corrections with some information to interpret the study results based on the multiple test correction approach used.

Finally, the authors would like to advise the reader that the study conclusions should not be considered as definitive. As mentioned in the article, the study findings should be interpreted with caution and further research is still needed to confirm them.

\section{Acknowledgements}

The authors would like to acknowledge the remaining investigators of the CRESCENDO Study Group participating in the study: Ana María López-Real (Complejo Hospitalario Universitario de A Coruña, A Coruña, Spain), Berta Sebastián-Torres (Hospital Universitario Miguel Servet, Zaragoza, Spain), Carmen Arnal-García (Hospital Universitario Virgen de las Nieves, Granada, Spain), Cristina Guijarro-Castro (Hospital Universitario 12 de Octubre, Madrid), Delicias Muñoz-García (Hospital Xeral Cíes, Vigo, Spain), Francisco Javier Barrero-Hernández (Hospital Universitario San Cecilio, Granada, Spain), Gerard Josep Mauri-Capdevila (Hospital Universitario Central de Asturias, Oviedo, Spain), Javier MalladaFrechin (Hospital General Universitario de Elda, Elda, Sapin), Jesús Foronda-Bengoa (Complejo Hospitalario de Jaén, Jaén, Spain), Jordi Batlle-Nadal (Hospital Sant Pau i Santa Tecla, Tarragona, Spain), José Andrés Domínguez-Morán (Hospital Universitario de la Ribera, Alzira, Spain), José María Prieto-González (Hospital Clínico Universitario de Santiago, Santiago de Compostela, Spain), José Marín-Marín (Hospital General Universitario Reina Sofía, Murcia, Spain), Laura Gubieras-Lillo (Hospital de Sant Joan Despí Moisès Broggi, Sant Joan Despí, Spain), Lluisa Rubio-Pérez (Hospital Universitario Príncipe de Asturias, Alcalá Henares, Spain), Lorena 
Citation: Olascoaga-Urtaza J, Meca-Lallana V, Hernández-Clares R, Ramió-Torrentà L, Pérez D, et al. (2014) Quality of Life, Depression, Sexual Dysfunction and Work Absenteeism in Relapsing-Remitting Multiple Sclerosis Patients Starting Glatiramer Acetate as First-Line Treatment: A Prospective Cohort Study. J Neurol Neurophysiol 5: 199. doi:10.4172/2155-9562.1000199

Page 8 of 9

García-Fernández (Hospital Clínico Universitario Lozano Blesa Zaragoza, Spain), Lucienne Costa-Frossard-França (Hospital Universitario Ramón y Cajal, Madrid, Spain), María RodríguezRodríguez (Complejo Hospitalario Xeral-Calde, Lugo, Spain), Miguel Ángel Tola-Arribas (Hospital Universitario Río Hortega, Valladolid, Spain), Olga Carmona-Codina (Fundació Salut Empordà, Figueres, Spain), Ramón Villaverde-González (Hospital General Universitario Morales Meseguer, Murcia, Spain), Sonia Mayra Gómez-Moreno (Hospital Universitario Infanta Leonor, Madrid, Spain) and Teresa Ayuso-Blanco (Hospital de Navarra, Pamplona, Spain).

Medical writing support was provided by Esther Álvarez-García and Antonio Torres-Ruiz at Dynamic S.L. during the preparation of this paper, funded by TEVA Pharmaceutical Ltd.

\section{Conflict of Interest and Sources of Funding Statement}

This work was funded by TEVA Pharmaceutical Ltd. Medical writing support provided by Dynamic S.L. was also funded by TEVA Pharmaceutical Ltd.

Javier Olascoaga-Urtaza has received grants for research projects and fees for participating in conferences/meetings/congresses from Almirall, Bayer, Biogen-Idec, Genzyme, Merck, Novartis and TEVA Pharmaceutical Ltd; and has participated in advisory boards for Biogen-Idec, Novartis and Genzyme. Lluís Ramió-Torrentà has received grants for research projects and fees for acting as a consultant/speaker from TEVA Pharmaceutical Ltd, Bayer-Schering, Biogen-Idec, Novartis and Merck-Serono. Noemi Llopis and Rainel Sánchez-de la Rosa are employees of TEVA Pharmaceutical Ltd, who work at Medical and Health Economics and Outcomes Research Department. The remaining authors of this manuscript declare no conflict of interest to disclose.

\section{References}

1. Isaksson AK, Ahlström G, Gunnarsson LG (2005) Quality of life and impairment in patients with multiple sclerosis. J Neurol Neurosurg Psychiatry 76: 64-69.

2. de Andrés C, Guillem A (2000) [Approach to quality of life changes in patients with multiple sclerosis]. Rev Neurol 30: 1229-1234.

3. Jaracz K, Pawlak M, Górna K, Kołcz B, Wołoszyn D, et al. (2010) Quality of life and social support in patients with multiple sclerosis. Neurol Neurochir Pol 44: 358-365.

4. Amato MP, Ponziani G, Rossi F, Liedl CL, Stefanile C, et al. (2001) Quality of life in multiple sclerosis: the impact of depression, fatigue and disability. Mult Scler 7: 340-344.

5. Goretti B, Portaccio E, Zipoli V, Hakiki B, Siracusa G, et al. (2009) Coping strategies, psychological variables and their relationship with quality of life in multiple sclerosis. Neurol Sci 30: 15-20.

6. Alshubaili AF, Ohaeri JU, Awadalla AW, Mabrouk AA (2008) Quality of life in multiple sclerosis: a Kuwaiti MSQOL-54 experience. Acta Neurol Scand 117: 384-392.

7. Kargarfard M, Eetemadifar M, Mehrabi M, Maghzi AH, Hayatbakhsh MR (2012) Fatigue, depression, and health-related quality of life in patients with multiple sclerosis in Isfahan, Iran. Eur J Neurol 19: 431-437.

8. Janardhan V, Bakshi R (2002) Quality of life in patients with multiple sclerosis: the impact of fatigue and depression. J Neurol Sci 205: 51-58.

9. Wang JL, Reimer MA, Metz LM, Patten SB (2000) Major depression and quality of life in individuals with multiple sclerosis. Int J Psychiatry Med 30: 309-317.

10. Fàbregas L, Planes M, Gras ME, Ramió-Torrentà L (2007) [Quality of life of patients with recently diagnosed multiple sclerosis: impact of physical and psychosocial variables]. Med Clin (Barc) 128: 355-356.
11. Nortvedt MW, Riise T, Myhr KM, Landtblom AM, Bakke A, et al. (2001) Reduced quality of life among multiple sclerosis patients with sexual disturbance and bladder dysfunction. Mult Scler 7: 231-235.

12. Tepavcevic DK, Kostic J, Basuroski ID, Stojsavljevic N, Pekmezovic T, et al. (2008) The impact of sexual dysfunction on the quality of life measured by MSQoL-54 in patients with multiple sclerosis. Mult Scler 14: 1131-1136.

13. Miller A, Dishon S (2006) Health-related quality of life in multiple sclerosis: The impact of disability, gender and employment status. Qual Life Res 15: 259-271.

14. Patti F, Pozzilli C, Montanari E, Pappalardo A, Piazza L, et al. (2007) Effects of education level and employment status on HRQoL in early relapsing-remitting multiple sclerosis. Mult Scler 13: 783-791.

15. Jongen PJ, Sindic C, Carton H, Zwanikken C, Lemmens W, et al. (2010) Improvement of health-related quality of life in relapsing remitting multiple sclerosis patients after 2 years of treatment with intramuscular interferon-beta-1a. J Neurol 257: 584-589.

16. Abolfazli R, Hosseini A, Gholami Kh, Javadi MR, Torkamandi H, et al (2012) Quality of Life Assessment in Patients with Multiple Sclerosis Receiving Interferon Beta-1a: A Comparative Longitudinal Study of Avonex and Its Biosimilar CinnoVex. ISRN Neurol 2012: 786526.

17. Vermersch P, de Seze J, Delisse B, Lemaire S, Stojkovic T (2002) Quality of life in multiple sclerosis: influence of interferon-betal a (Avonex) treatment. Mult Scler 8: 377-381

18. Patti F, Amato MP, Trojano M, Bastianello S, Tola MR, et al. (2011) Quality of life, depression and fatigue in mildly disabled patients with relapsing-remitting multiple sclerosis receiving subcutaneous interferon beta-1a: 3-year results from the COGIMUS (COGnitive Impairment in MUltiple Sclerosis) study. Mult Scler 17: 991-1001.

19. Zivadinov R, Zorzon M, Tommasi MA, Nasuelli D, Bernardi M, et al. (2003) A longitudinal study of quality of life and side effects in patients with multiple sclerosis treated with interferon beta-1a. J Neurol Sci 216 : 113-118.

20. Simone IL, Ceccarelli A, Tortorella C, Bellacosa A, Pellegrini F, et al. (2006) Influence of Interferon beta treatment on quality of life in multiple sclerosis patients. Health Qual Life Outcomes 4: 96.

21. Jongen PJ, Lehnick D, Sanders E, Seeldrayers P, Fredrikson S, Andersson $\mathrm{M}$, et al. (2010) Health-related quality of life in relapsing remitting multiple sclerosis patients during treatment with glatiramer acetate: a prospective, observational, international, multi-centre study. Health Qual Life Outcomes 8:133.

22. Kurtzke JF (1983) Rating neurologic impairment in multiple sclerosis: an expanded disability status scale (EDSS). Neurology 33: 1444-1452.

23. Aymerich M, Guillamon I, Perkal H, Nos C, Porcel J, et al. (2006) [Spanish adaptation of the disease-specific questionnaire MSQOL-54 in multiple sclerosis patients]. Neurologia 21: 181-187.

24. Vickrey BG, Hays RD, Harooni R, Myers LW, Ellison GW (1995) A health-related quality of life measure for multiple sclerosis. Qual Life Res 4: 187-206.

25. Beck AT, Ward CH, Mendelson M, Mock J, Erbaugh J (1961) An inventory for measuring depression. Arch Gen Psychiatry 4: 561-571.

26. Vázquez C, Sanz J (1999) Fiabilidad y evaluación de la versión española del inventario para la depresión de Beck 1978 en pacientes con trastornos psiquiátricos. Clínica y Salud 10: 59-81.

27. Multiple Sclerosis International Federation. www.msif.org/docs/ MSISQ19_ES.doc (accessed 4/3/2013).

28. Sanders AS, Foley FW, LaRocca NG, Zemon V (2000) The multiple sclerosis intimacy and sexuality questionnaire-19 (MSISQ-19). Sexuality and Disability 18: 3-26.

29. Perneger TV (1998) What's wrong with Bonferroni adjustments. BMJ 316: $1236-1238$

30. Rothman KJ (1990) No adjustments are needed for multiple comparisons. Epidemiology 1: 43-46. 
Citation: Olascoaga-Urtaza J, Meca-Lallana V, Hernández-Clares R, Ramió-Torrentà L, Pérez D, et al. (2014) Quality of Life, Depression, Sexual Dysfunction and Work Absenteeism in Relapsing-Remitting Multiple Sclerosis Patients Starting Glatiramer Acetate as First-Line Treatment: A Prospective Cohort Study. J Neurol Neurophysiol 5: 199. doi:10.4172/2155-9562.1000199

Page 9 of 9

31. Fernández-Fernández Ó, Garcia-Trujillo L, Guerrero-Fernández M, León A, López-Madrona JC, et al. (2012) The effectiveness of glatiramer acetate in clinical practice: an observational study. Rev Neurol 54: 1-9.

32. Haas J, Firzlaff M (2005) Twenty-four-month comparison of immunomodulatory treatments - a retrospective open label study in 308 RRMS patients treated with beta interferons or glatiramer acetate (Copaxone). Eur J Neurol 12: 425-431.

33. Ford C, Goodman AD, Johnson K, Kachuck N, Lindsey JW, et al. (2010) Continuous long-term immunomodulatory therapy in relapsing multiple sclerosis: results from the 15-year analysis of the US prospective openlabel study of glatiramer acetate. Mult Scler 16: 342-350.

34. Olascoaga J (2010) [Quality of life and multiple sclerosis]. Rev Neurol 51: 279-288.

35. Ziemssen T, Hoffman J, Apfel R, Kern S (2008) Effects of glatiramer acetate on fatigue and days of absence from work in first-time treated relapsing-remitting multiple sclerosis. Health Qual Life Outcomes 6: 67.

36. Lage MJ, Castelli-Haley J, Oleen-Burkey MA (2006) Effect of immunomodulatory therapy and other factors on employment loss time in multiple sclerosis. Work 27: 143-151.

37. Tsai SJ (2007) Glatiramer acetate could be a potential antidepressant through its neuroprotective and anti-inflammatory effects. Med Hypotheses 69: 145-148.
38. Ziemssen T (2009) Multiple sclerosis beyond EDSS: depression and fatigue. J Neurol Sci 277 Suppl 1: S37-41.

39. Meca-Lallana JE, Balseiro JJ, Lacruz F, Guijarro C, Sanchez O, et al. (2012) Spasticity improvement in patients with relapsing-remitting multiple sclerosis switching from interferon- $\beta^{2}$ to glatiramer acetate: the Escala Study. J Neurol Sci 315: 123-128.

40. Ziemssen T, Carra A, de Klippel N, de Sa J, Frederiksen J, et al. (2011) Insights from the Coptimize Study: characteristics of relapsing-remitting multiple sclerosis (RRMS) patients switching to glatiramer acetate. 63rd Annual Meeting of the American Academy of Neurology Honolulu, Hawai 2011.

41. Ziemssen T, Penner IK, Hoffman JA, Calabrese P (2011) Monitoring quality of life, fatigue and cognition in RRMS patients during treatment with glatiramer acetate (QualiCOP study). 5th Joint Triennial Congress of the European and Americas Committees for Treatment and Research in Multiple Sclerosis Amsterdam, The Netherlands.
This article was originally published in a special issue, entitled:

"Neurodegenerative Diseases: Symptoms and Therapeutics", Edited by Dr. Jin J Luo, Temple University School of Medicine, USA 